\title{
DC Link Voltage Effects on the Performance of the Two Current Control Strategies of Voltage Source Converters
}

\author{
Hesam Rahbari Magham, Erfan Ma'ali Amiri, Javad Shokrollahi Moghani, \\ Babak Abdi, and G. B. Gharehpetian \\ Electrical Engineering Department, Amirkabir University of Technology, Tehran, Iran \\ Phone/Fax number: +98-21-64543504 \\ h.rahbarim@aut.ac.ir
}

\begin{abstract}
This paper investigates the effects of the DC link voltage of a voltage source converter (VSC)on the performance oftwo current control strategies of the VSCsfrom point of views: capability of tracking the references signals with a zero steady-state error and imposing less transients during the step changes in the references signals of the controllers. Two conventional and multivariable proportional-integral (PI) based $d q$ current controllerstrategy has been represented. Then based on the considering the worst step changes in the references signals of the VSC while the DC link voltage $\left(V_{d c}\right)$ is varying, a specified range has been obtained for the $V_{d c}$. It has been depicted thatthe multivariable control strategy has less transient and more decoupling capability between $d$ and $q$ axis components of the current during the step changes which have been occurred in the various DC link voltage of the VSC. Alsofor tracking the reference signals, $V_{d c}$ of the inverter must be in a particular range.Otherwise tracking the reference signals verifies that the axes are not fully decoupled or in some cases the system would be unstable.
\end{abstract}

Keywords: DC link voltage, voltage source converter, Multivariable control strategy

\section{Introduction}

Power inverters with regulated input currents are widely utilized in many grid interfaced systems, e.g., photovoltaic power applications [1], and wind energy [2], active power filters [3]-[4], power-factor controllers [5]-[6], high voltage direction current (HVDC) applications [7], etc. In most of such systems, a VSC is interfaced to the utility grid through a line reactor filter, and a current regulation strategy is adopted by the VSC to control its output current.On the other hand the DC link voltage has greatly impact on the performance of the tracking the reference signals with a zero steady-state error in VSC controllers.In the literatures, various current regulation approaches for the VSCs have been proposed. e.g. hysteresis, deadbeat, predictive, and proportional-integral (PI) and proportional-resonant (PR)-based control strategies [8]. Two classes of these approaches are: 1) stationary reference frame controller and 2 ) and rotating reference frame controller. Among the stationary-frame controller (SRF), the simple and linear proportional-integral (PI) controllers are considered as the most conventional approach. However due to nonzero steady-state error, PR controllers [9]-[10] have been proposed. Current regulating in rotating reference frame (RRF) where defined when time varying variables (AC variables) transfer to an orthogonal space like $d-q$ domain which variables appear as time invariant quantities allowing where the designed controller act like a DC/DC converter with zero steady state error by providing an infinite gain at the operating point. In these methods the capability of utilized controllers in decoupling the two distinct $d-q$ axes from each other such that the unwanted disturbances applied to one axes do not generate transients on the other one [11], [12] and [13]. PI-based current regulation scheme for VSCs, i.e. multivariable PI-based control strategy, provides the $d$ and $q$ axes almost fully decoupled such that the step changes in one axis negligibly affect the other one [14]. The both methods have the following characteristics: 1) fast dynamics and a zero steady-state error, and 2) are

Received: January $28^{\text {th }}, 2013$. Accepted: March $30^{\text {th }}, 2013$ 
structurally simple. Regarding to importance of tracking the references signals in the controllers, investigating the effects of the system parameters on the operation of these controllers is significant. As it is known, because of the extensive utilizing of the inverter based distributed generations (DG) by utilities, VSCs are one of the most important components in the power systems [15], [16] and [17]. Moreover one of the important parts of the VSCs is the DC link voltagethat can control the output variables of the unit. Therefore it should be controlled more accurately as possible [18], [19] and [20].

In this paper the performance of these two control strategies has been evaluated against the change of the DC link voltage. The superiority of the multivariable control strategy than the conventional approach has been proved because of preparing fewer transients in addition to regulating the $d-q$ components of the output line current at the desired level faster than the conventional control strategy and almost with zero steady state error. Therefore during the $V_{d c}$ changing process as an importantparameter of the system, the output current and voltage waveform of the VSC are accompany with lower distortion and much less transient in the multivariable control strategy. Due to consecutive changing of the $V_{d c}$, a specified range for each of the control strategy has been achieved. However thisrange has obtained for a sample case study with typical parameter values, but the procedure of this method in the various systems could be effective to choosing the type and capacity of the DG unit.

\section{Overviewing of the two current control strategies of VSC}

A one-line diagram of the test system is depicted in Figure 1. The system parameters are given in Table I. The dynamic represent of the VSC output variables respect to the point of common coupling (PCC) can be described in ab0 domain as bellows: [14]

$$
V_{t, a b c}=R_{t} i_{t, a b c}+L_{t} \frac{d i_{t, a b c}}{d t}+V_{a b c}
$$

Separating the real and imaginary terms, the dynamics of the $\mathrm{d}$ and $\mathrm{q}$ axes are deduced

$$
\begin{aligned}
& R_{t} i_{t, d}+L_{t} \frac{d i_{t, d}}{d t}=V_{t, d}+\omega L_{t} i_{t, q}-V_{d} \\
& R_{t} i_{t, q}+L_{t} \frac{d i_{t, q}}{d t}=V_{t, q}-\omega L_{t} i_{t, d}-V_{q}
\end{aligned}
$$

According to (2) and (3), the structural diagram of Figure 2, in the rotating reference frame is obtained, which contains the typical coupling terms.

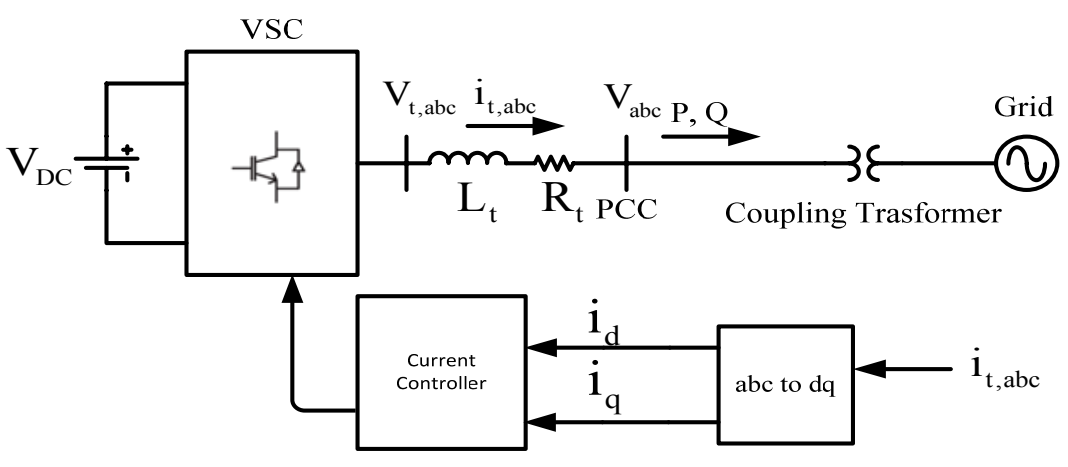

Figure 1. One-line diagram of the test system. 
Table1. Parametersof thethree-phasesystem

\begin{tabular}{|c|c|c|}
\hline Quantity & value & Comment \\
\hline $\mathrm{L}_{\mathrm{t}}$ & $4.5 \mathrm{mH}$ & Inductance of VSC Filter \\
$\mathrm{R}_{\mathrm{t}}$ & $0.1 \Omega$ & Resistance of VSC Filter \\
\hline $\mathrm{V}_{\mathrm{dc}}$ & $450 \mathrm{~V}$ & DC Bus Voltage \\
$\mathrm{V}_{\mathrm{s}}$ & $350 \mathrm{~V}$ & Grid Nominal Phase Voltage \\
\hline $\mathrm{f}_{\mathrm{sw}}$ & $10 \mathrm{KHz}$ & PWM Carrier Frequency \\
$\mathrm{f}_{\mathrm{s}}$ & $5 \mathrm{KHz}$ & Sampling Frequency \\
$\mathrm{f}$ & $50 \mathrm{~Hz}$ & System Nominal Frequency \\
$\omega$ & $314.15 \mathrm{rad} / \mathrm{s}$ & Nominal Angular Frequency \\
\hline
\end{tabular}

A. Conventional dq Current Controller

Based on (2) and (3), in order to achieve decoupled control of $i_{d}$ and $i_{q}$, the converter voltage should be controlled as follows:

$$
u_{t, d}=u_{c, d}-L_{t} \omega i_{t, q}+v_{d}(4) u_{t, q}=u_{c, q}+L_{t} \omega i_{t, d}+v_{q}(5)
$$

in which $u_{c d}$ and $u_{c q}$ represent the control signals.

Finally, the transfer function of the decoupled system is derived as follows, in which the time constant $T_{s}$ is equal to $L / R$, and $K_{s}=1 / R[14]$ :

$$
\begin{aligned}
& G_{s}(s)=\frac{K_{s}}{1+s T_{s}} \\
& G_{P E}^{s}(s)=\frac{K_{c m}}{1+s T_{P E}} \\
& G_{o}(s)=G_{R}(s) G_{P E}(s) G_{S}(s)
\end{aligned}
$$

The transfer function $G_{R}(s)$ of the conventional PI controller defined to be as bellows:

$$
G_{R}(s)=\frac{1+s T_{n}}{s T_{i}}
$$

where $T_{i}$ the integration is time constant and is determined by considered phase margin for system transfer function $G_{o}(s)$. According to (4) and (5), the structural diagram of the current regulator based on PI controllers is shown in Figure 3 in which the voltage feedforward and the coupling terms are shown.

Adopting the feedforward signals theoretically results in a fully decoupled system. This perfect decoupling can be achieved only if the feedforward signals can precisely cancel the effect of the coupling terms, i.e., $\omega L_{t} i_{d}$ and $\omega L_{t} i_{q}$.

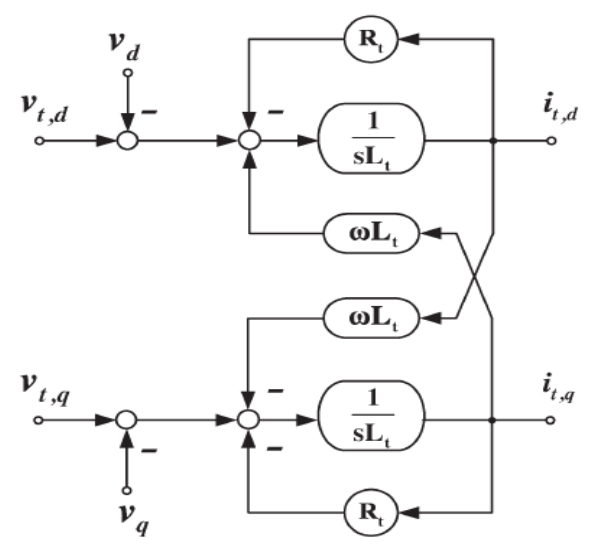

Figure 2. Structural diagram of the test system in the RRF. 


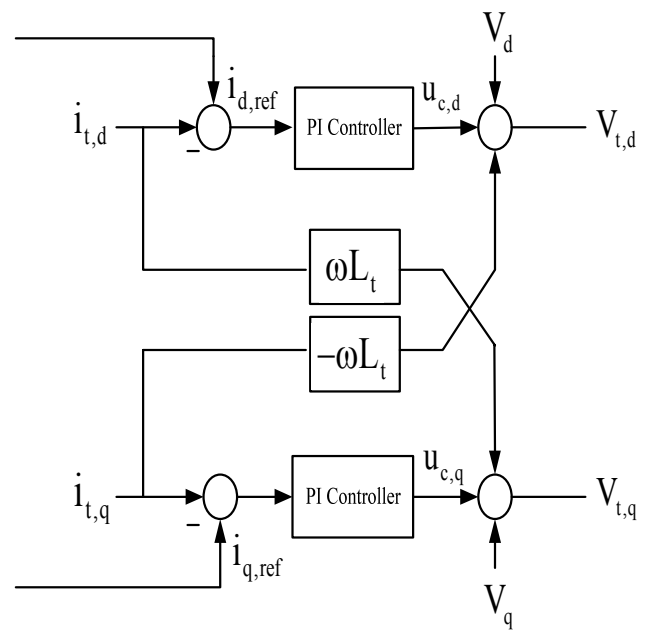

Figure 3. Structural diagram of the conventional dq current controller.

\section{B. Multivariable-PI dq Current Controller}

To designing the multivariable PI current controller first the dynamic representation of the converter output respect to the PCC bus in Laplace domain is written as Eq. (10) and the plant inversion technique has been utilized as follows.

$$
V_{t}(s)=R_{t} I_{t}(s)+L_{t} s I_{t}(s)+j \omega L_{t} I_{t}(s)+V_{P C C}(s)
$$

If the PCC bus voltage assumed to be almost fixed by the VSC, VPCC could be subtracted from both side of the Eq. (10) to canceling its effect. Therefore according to Eq. (10) the transfer function of the system which its model has been obtained in Figure 2 could be represented as bellows:

$$
G_{s}(s)=\frac{V_{t}-V}{I_{t}}=\frac{K_{s}}{1+(s+j \omega) T_{s}}
$$

The term $j \omega T$ Ts represent the coupling between two $d$ and q axes component of the output current. The open loop transfer function of the system could be multiplying of the controller and system transfer function and a transfer function that represent the behavior of the pulse width modulation moreover the sampling and measurements time delay [21]. Therefore to eliminating the coupling between two axes a zero-pole cancelation to removing the terms contain $j \omega$ in (11) is performed thus the open loop transfer function can be deduced as follows:

$$
G_{o}(s)=\frac{K}{s T_{i}\left(1+s T_{P E}\right)}
$$

Decomposing the real and imaginary parts of the transfer function (12) to obtain the control signals in the $\mathrm{d}$ and $\mathrm{q}$ direct axis, results the following expressions:

$$
u_{c, d}=\frac{1+s T_{n}}{s T_{i}} i_{\varepsilon, d}-\frac{\omega T_{n}}{s T_{i}} i_{\varepsilon, q}
$$




$$
u_{c, q}=\frac{1+s T_{n}}{s T_{i}} i_{\varepsilon, q}+\frac{\omega T_{n}}{s T_{i}} i_{\varepsilon, d}
$$

It can be inferred where the integrators which have been applied on the coupling terms in the control signals can significantly reduce the effect of each axis on another one. Therefore according to Eq. (13) and (14) the block diagram of the multivariable control strategy has been shown in Figure 4.

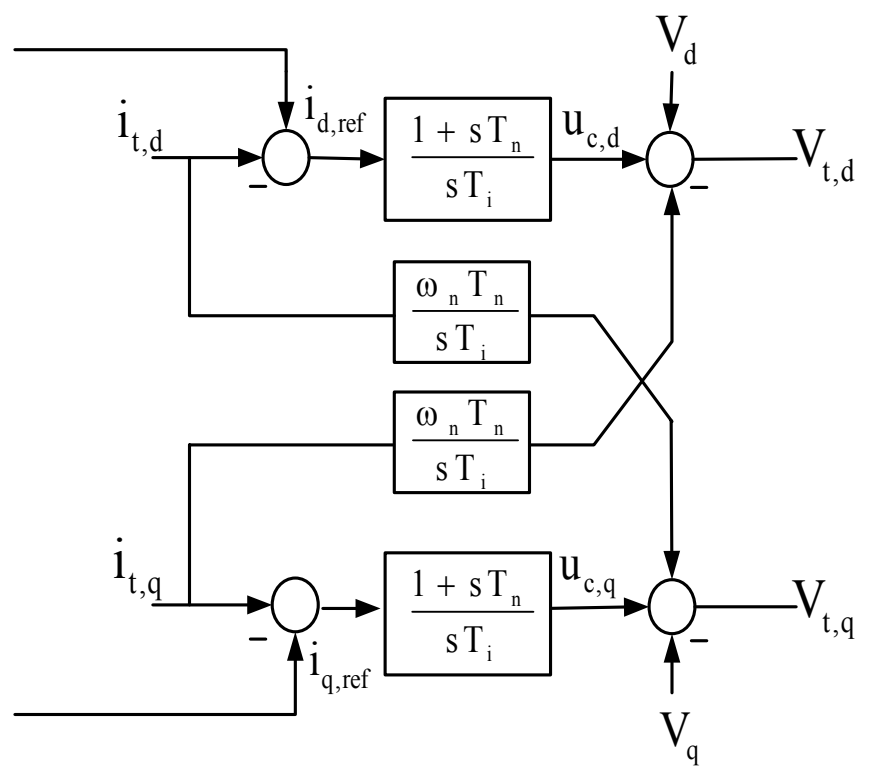

Figure 4. Structural diagram of multivariable-PI controller with voltage feedforward [14].

\section{DC link voltage effects on the performance of the two current control strategies of VSCs in tracking the reference signals}

The voltage source converter in a power system can be considered as a fast controllable machine whose fundamental frequency output voltage is given by:

$$
\left(V_{t, a b c}\right)_{1}=\frac{1}{2} m_{a} V_{d c} \sin (w t+\varphi)
$$

where $m_{a}$ is modulation index, $\omega$ is the fundamental frequency and $\varphi$ is the phase shift of the output voltage, $V_{t}$.In the previous literatures the performance of the DC link voltage has been investigated without considering the VSC control strategies and also a minimum and maximum value has been obtained [22]. But it is necessary to considering the effect of the controllers and the feedbacks which has been utilized in the different parts of the system. According to the Eq. (15), the VSC output voltage has an intensive dependency to the $m_{a}$. Since the $m_{a}$ is affected by the voltage control signals of the VSC switches, and moreover these control signals are obtain by the $v_{d}$ and $v_{q}$ components of the output voltage. Therefore these control feedbacks have a significant impact on the study. Because of the control system is multi input, multi output (MIMO), the theoretical analysis for such systems appears difficult. However due to the structure of the multivariable control strategy, where it has been added an integrator in the decoupling blocks, it is expected that against the various DC link voltage, the controller has better and smoother performance. The effect of the DC link voltage for each type of the conventional and multivariable control strategy has been investigated and compared to each other. And for the typical case study, the range of the $V_{d c}$ for the best operation of the VSC has been achieved. 
The purpose of this section is to review DC link voltage effects on the performance of the two current control strategies of VSCs in tracking the reference signals with a zero steady-state error, and finally present an optimal value for $V_{d c}$ based on stimulation results. Simulation results show that both controller strategiesin different standard ranges of $V_{d c}$ have the following characteristics: 1) are capable of tracking the reference signals with a zero steady-state error;2) have fast dynamics; 3) provide practically decoupled $d$ and $q$ current axes.

To survey theDC link voltage effects on the performance of the two current controllers, two sets of tests are conducted for each control strategy: 1) step-down and step-up in the d-axis reference value while that of the q-axis is kept constant and 2) step-down and step-up in the qaxis reference value while that of the d-axis is kept constant.

\section{Simulation Results}

To investigating theDC link voltage effects on the performance of the outlined current control schemes, a simulation study is conducted in MATLAB/Simulink software environment. The test system of Figure 1 is utilized, and its parameters are set based on Table 1.

\section{A. First Test: Reference-Tracking Test in d-Axis}

In this section, the performance of both current regulation schemes is evaluated subsequent to two step changes in the reference value of the d-axis during different value of DC link voltage. It is shown that, for each special value of $V_{d c}$ in both control strategies, subsequent to the step changes in the d-axis, a different transient is experienced in the $q$ one, which verifies that DC link voltage effects on the performance of both strategies and limited range of $V_{d c}$ imposes much less transients on the q-axis.

\section{A.1 Conventional Controller}

The VSC in Figure1 initially injects 0.5 p.u. of the q-component and -0.2 p.u. of the dcomponent of the currents. At the time instant of $0.3 \mathrm{~s}$, the d-component steps up to -0.9 p.u., Moreover, at $\mathrm{t}=0.35 \mathrm{~s}$, the $\mathrm{d}$-axis reference value is set back to $-0.2 \mathrm{p}$.u. while the reference value for the q-component is kept constant during the whole process.

Figure 5 shows at $V_{d c}=400 \mathrm{v}$ upon each step change, the line currents and their corresponding d-component change to track the reference value changes with a zero steadystate error, as shown in Figure5(a) and (b). Although the reference value of the q-axis is constant, however, subsequent to each change in the d-axis, the q-axis also experiences transients, which are almost negligible, as shown in Figure 5(c). The latter transients verify that the conventional current control strategy at $V_{d c}=400 \mathrm{v}$ doesn't suffer from coupled axes.

Figure 6 showswhere at $V_{d c}=200 \mathrm{v}$ upon each step change, the line currents and their corresponding d-component change to track the reference value changes with a zero steadystate error, as shown in Figure 6(a) and (b). Although the reference value of the q-axis is constant, however, subsequent to each change in the d-axis, the q-axis also experiences transients, which are negligible, as shown in Figure 6(c). The latter transients verify that the conventional current control strategy at $V_{d c}=200 \mathrm{v}$ imposes much less transients on the q-axis and selecting this value for $V_{d c}$ is suitable for this strategy.

For $V_{d c}=100$, a test similar to what is conducted in previous Sections is carried out. That simulation results are shown in Figure 7.It shows subsequent to each change in the d-axis, the reference value of the q-axis isn't constant. The transients verify that this strategy at $V_{d c}=100 \mathrm{v}$ suffer from coupled axes.

\section{A.2 Multivariable-PI Controller}

The test system of Figure 1 initially injects 0.5 p.u. of the q-component and -0.2 p.u. of the d-component of the currents. Keeping the q-axis reference value constant, at the time instant of 
(a)

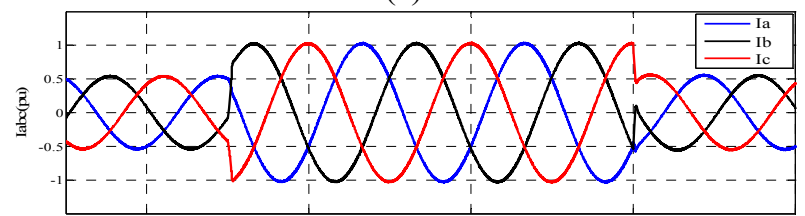

(b)

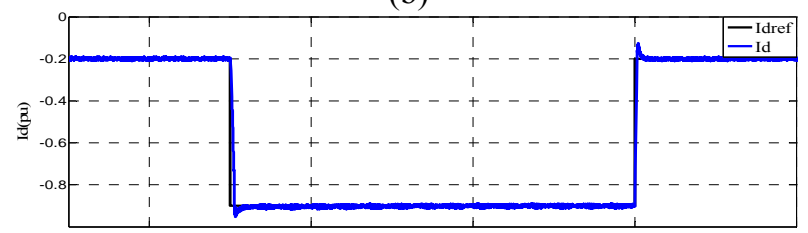

(c)

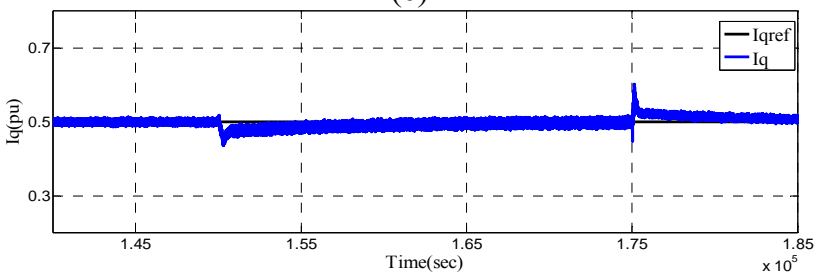

Figure 5. Simulation results of the transient response of the conventional controller during step changes in d-axis at $V_{d c}=400 \mathrm{~V}$. (a) Line currents. (b) d-component of the currents. (c) qcomponents of the currents.

(a)

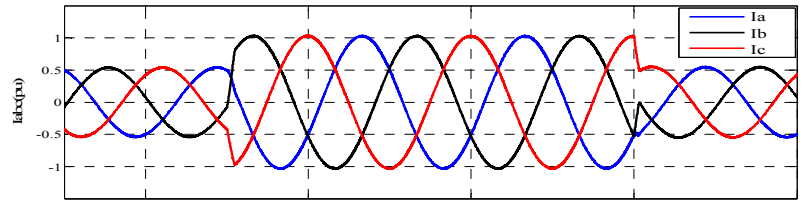

(b)

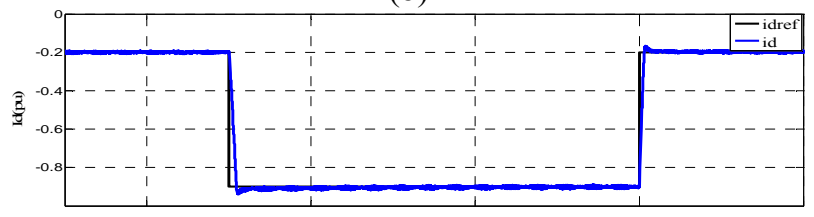

(c)

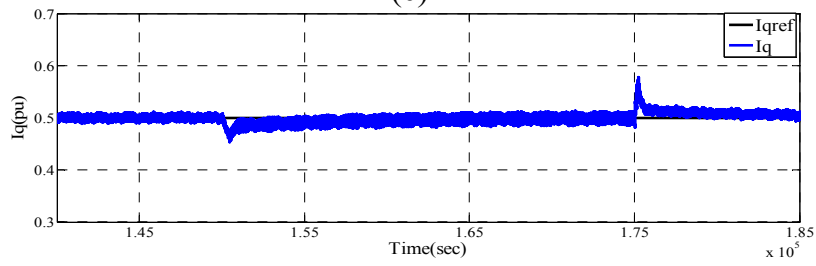

Figure 6. Simulation results of the transient response of the conventional controller during step changes in d-axis at $V_{d c}=200 \mathrm{~V}$. (a) Line currents. (b) d-component of the currents. (c) qcomponents of the currents. 
(a)

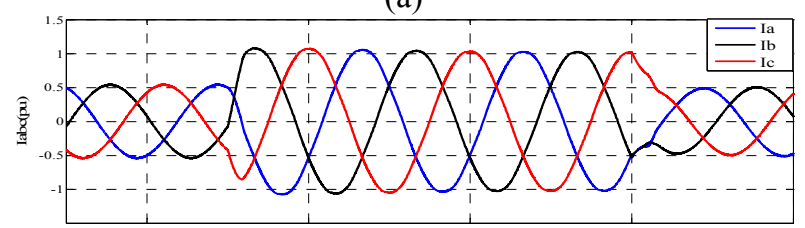

(b)

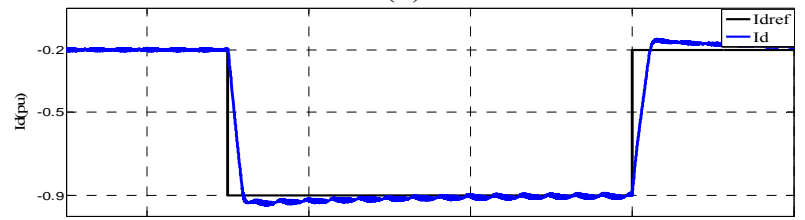

(c)

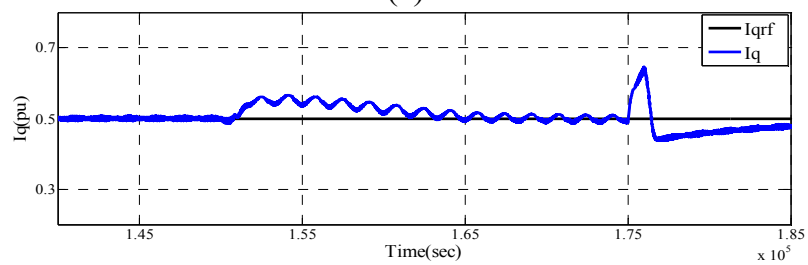

Figure 7. Simulation results of the transient response of the conventional controller during step changes in d-axis at $V_{d c}=100 \mathrm{~V}$. (a) Line currents. (b) d-component of the currents. (c) qcomponents of the currents.

(a)

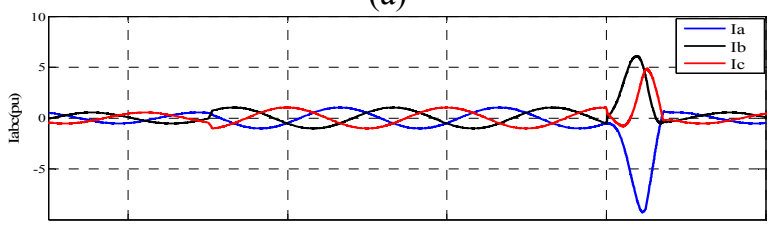

(b)

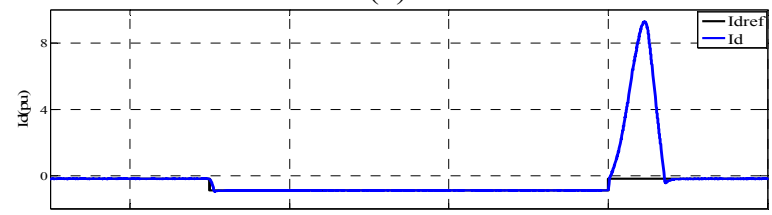

(c)

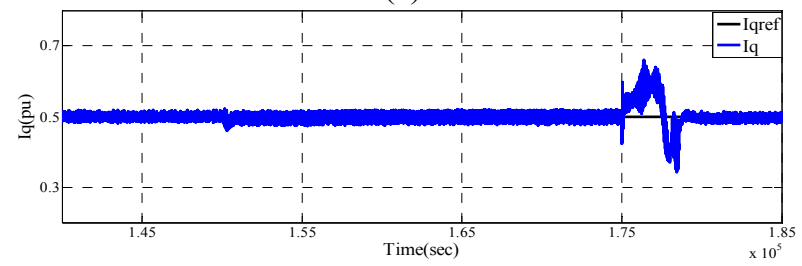

Figure 8. Simulation results of the transient response of the multivariable-PI controller during step changes in d-axis at $V_{d c}=700 \mathrm{~V}$. (a) Line currents. (b) d-component of the currents. (c) qcomponents of the currents. 
$0.3 \mathrm{~s}$, the d-component steps up to -0.9 p.u., and at $\mathrm{t}=0.35 \mathrm{~s}$, it steps down to -0.2 p.u. Figure 8 depicts at $V_{d c}=700 \mathrm{v}$ upon to each change in the d-axis reference value, the controller regulates the currents at the desired level, as shown in Figure 8(a) and Figure 8(b) depicts that, subsequent to each step change in the d-axis, the d-component of the currents is regulated at the desired level with a zero steady state error. However both of them experience unsuitable transients. Subsequent to each change in the d-axis, the q-axis also experiences transients, which are not negligible as shown in Figure 8(c). The latter transients verify that selecting this value for $V_{d c}$ is not suitable for the multivariable-PI current control strategy.

And Figure 9 depicts at $V_{d c}=200 \mathrm{v}$ upon each step change in the d-axis, the d-component of the currents is regulated at the desired level with a zero steady-state error, as shown in Figure 9(a) and (b). Subsequent to each change in the d-axis, the q-axis also experiences transients, which are negligible, as shown in Figure 9(c). The latter transients verify that the multivariable-PI current control strategy at $V_{d c}=200 \mathrm{v}$ imposes much less transients on the qaxis.

(a)

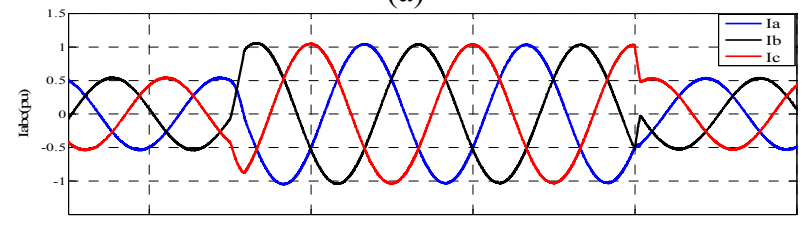

(b)

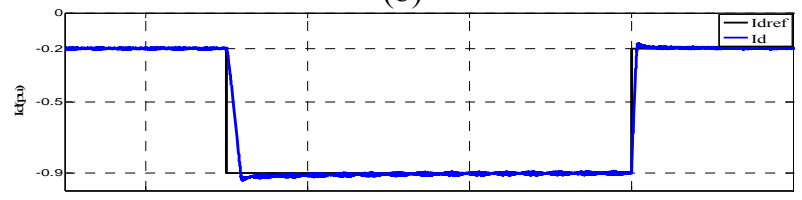

(c)

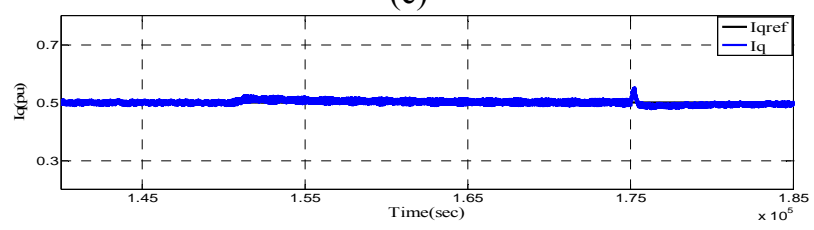

Figure 9. Simulation results of the transient response of the multivariable-PI controller during step changes in d-axis at $V_{d c}=200 \mathrm{~V}$. (a) Line currents. (b) d-component of the currents. (c) qcomponents of the currents.

For $V_{d c}=100$, a test similar to what is conducted in previous Sections is carried out. That simulation results are shown in Figure 10. It shows this value for $V_{d c}$ is not suitable for this strategy because subsequent to each change in the d-axis, the reference value of the q-axis isn't constant. 
(a)

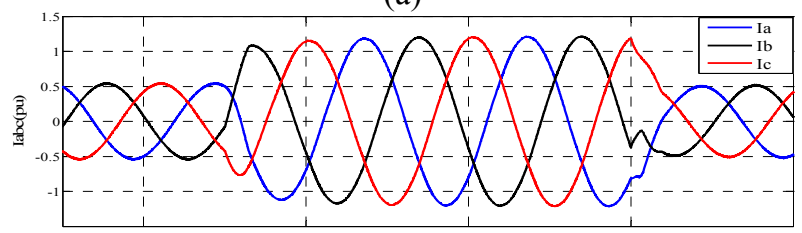

(b)

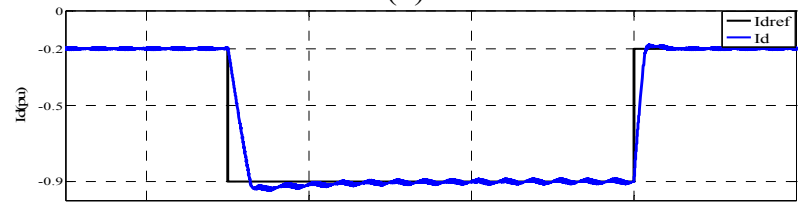

(c)

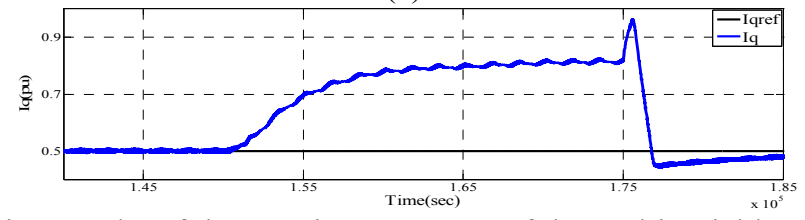

Figure 10. Simulation results of the transient response of the multivariable-PI controller during step changes in d-axis at $V_{d c}=100 \mathrm{~V}$. (a) Line currents. (b) d-component of the currents. (c) qcomponents of the currents.

\section{B. Second Test: Reference-Tracking Test in q-Axis}

In this section, similar to the previous test to reviews DC link voltage effects on the performance of the outlined current control strategies it is shown that, subsequent to the step changes in the q-axis, a transient is experienced in the $d$ one, which verifies that the axes are not fully decoupled. While, this transient is affected by $V_{d c}$, and special range of $V_{d c}$ imposes much less transients on the d-axis.

\section{B.1 Conventional Controller}

The VSC in Figure 1 initially injects- 0.5 p.u. of the d-component and -0.2 p.u. of the dcomponent of the currents. At the time instant of $0.3 \mathrm{~s}$, the q-component steps up to -0.9 p.u., Moreover, at $t=0.35 \mathrm{~s}$, the $q$-axis reference value is set back to $-0.2 \mathrm{p}$.u. while the reference value for the d-component is kept constant during the whole process.

Figure 11 shows at $V_{d c}=400 \mathrm{v}$ upon each step change, the line currents and their corresponding $q$-component change to track the reference value changes with a zero steadystate error, however both of them experience unsuitable transients, as shown in Figure 10(a) and (b). Although the reference value of the $d$-axis isn't constant, as shown in Figure 11(c), this failure to track the reference value verifies that this value for $V_{d c}$ is not suitable for this controller. Figure 12 shows at $V_{d c}=200 \mathrm{v}$ upon each step change, the line currents and their corresponding q-component change to track the reference value changes with a zero steadystate error, as shown in Figure 12(a) and (b). Although the reference value of the $d$-axis is constant, however, subsequent to each change in the $q$-axis, the $d$-axis also experiences transients, which are negligible, as shown in Figure 12(c). The latter transients verify that the conventional current control strategy at $V_{d c}=200 \mathrm{v}$ imposes much less transients on the d-axis, and selecting this value for $V_{d c}$ is suitable for Conventional Controller. 
(a)

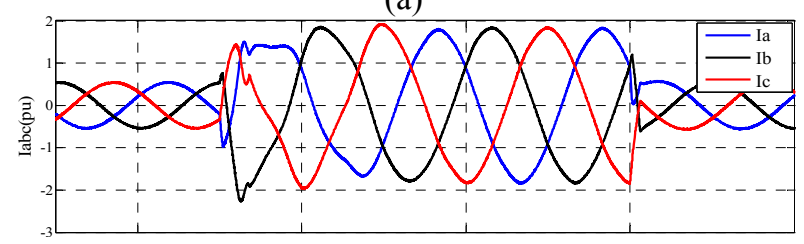

(b)

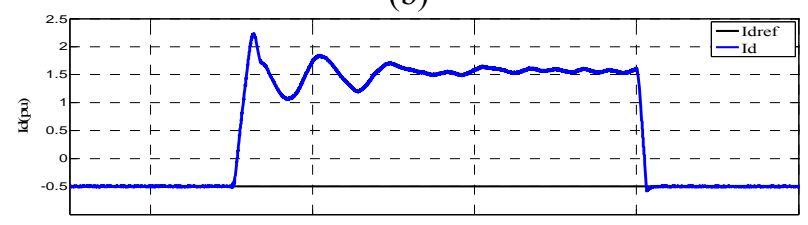

(c)

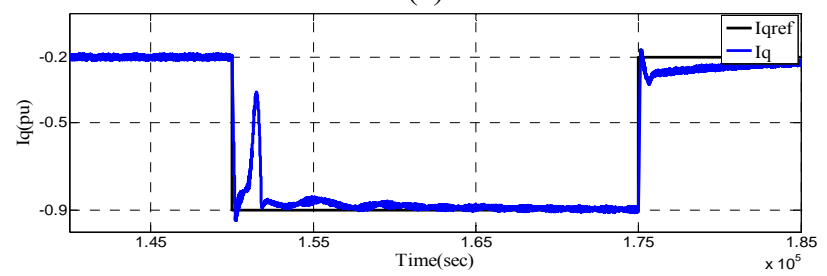

Figure 11. Simulation results of the transient response of the conventional controller during step changes in q-axis at $V_{d c}=400 \mathrm{~V}$. (a) Line currents. (b) d-component of the currents. (c) qcomponents of the currents.

(a)

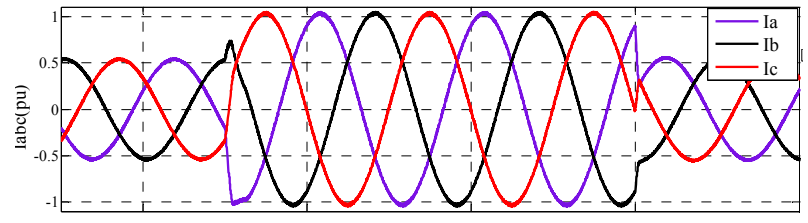

(b)

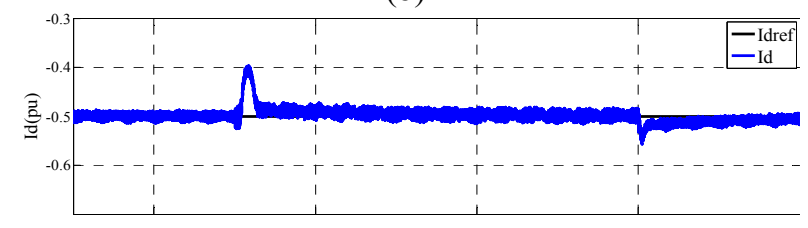

(c)

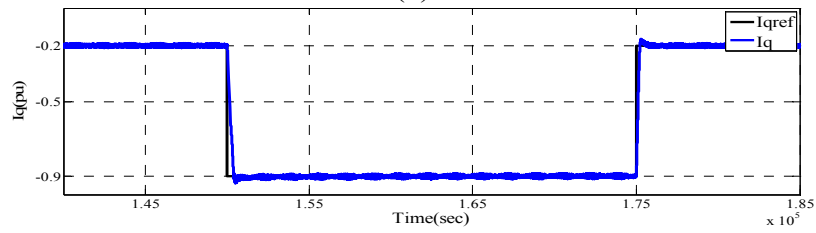

Figure 12. Simulation results of the transient response of the conventional controller during step changes in q-axis at $V_{d c}=200 \mathrm{~V}$. (a) Line currents. (b) d-component of the currents. (c) qcomponents of the currents. 
For $V_{d c}=100$, a test similar to what is conducted in previous Sections is carried out, that simulation results are shown in Fig 13. Subsequent to each change in the d-axis reference value, the controller regulates the currents at the desired level, as shown in Figure 13(a). Figure 13(b)depicts that, subsequent to each step change in the $d$-axis, the $d$-component of the currents isn't regulated at the desired level, this failure to track the reference values verify that this value for $V_{d c}$ is not suitable for this controller.

(a)

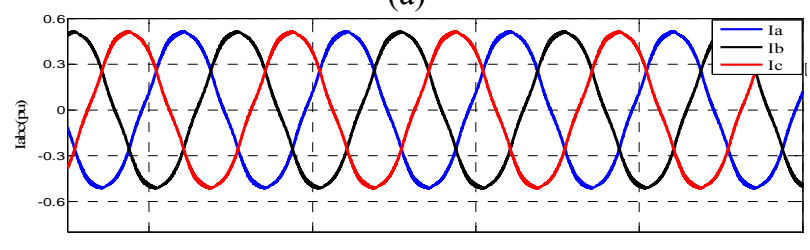

(b)

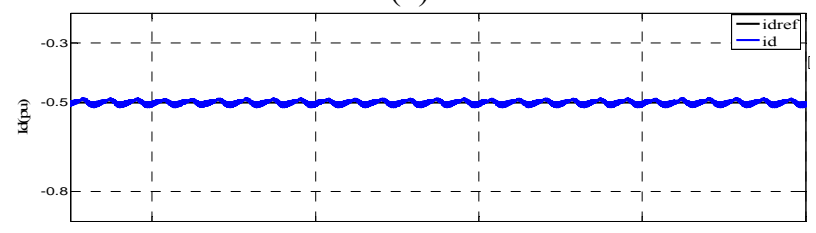

(c)

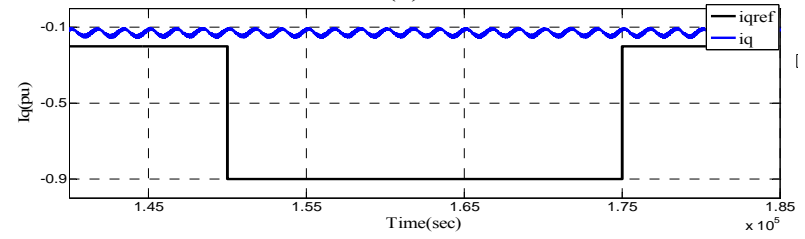

Figure 13. Simulation results of the transient response of the conventional controller during step changes in q-axis at $V_{d c}=100 \mathrm{~V}$. (a) Line currents. (b) d-component of the currents. (c) qcomponents of the currents.

\section{B.2 Multivariable-PI Controller}

The test system of Figure1 initially injects -0.5 p.u. of the d-component and -0.2 p.u. of the q-component of the currents. Keeping the d-axis reference value constant, at the time instant of $0.3 \mathrm{~s}$, the q-component steps up to -0.9 p.u., and at $\mathrm{t}=0.35 \mathrm{~s}$, it steps down to -0.2 p.u.

Figure 14 shows at $V_{d c}=700 \mathrm{v}$ upon each step change, the line currents and their corresponding q-component change to track the reference value changes with a zero steady-state error, as shown in Figure14(a) and (b). However, both of them experience unsuitable transients. Subsequent to each change in theq-axis, the d-axis also experiences transients, which are not negligible as shown in Figure 14(c). The latter transients verify that selecting this value for $V_{d c}$ is not suitable for the multivariable-PI strategy.

Figure15 depicts at $V_{d c}=200 \mathrm{v}$, upon to each change in the q-axis reference value, the controller regulates the currents at the desired level, as shown in Figure 15(a) and Figure 8(b) depicts that, subsequent to each step change in the q-axis, the q-component of the currents is regulated at the desired level with a zero steady state error. Subsequent to each change in the qaxis, the d-axis also experiences transients, which are negligible, as shown in Figure 15(c). The latter transients verify that the multivariable-PI current control strategy at $V_{d c}=200 \mathrm{v}$ imposes much less transients on the d-axis.

For $V_{d c}=100$, a test similar to what is conducted in previous sections is carried out. Simulation results are shown in Figure16. The results are similar to Conventional Controller results so this value for $V_{d c}$ is not suitable for multivariable-PI controller. 
Note that what was discussed in the previous sections were a series of specific step changes in the reference value that performance of two discussed controllers compared and reviewed based on them and finally a suitable value for $V_{d c}$ is presented. But generally, according to the worst step changes in reference value in which reference signals tracking may be not occurred, it is possible to present an acceptable range for $V_{d c}$.

(a)

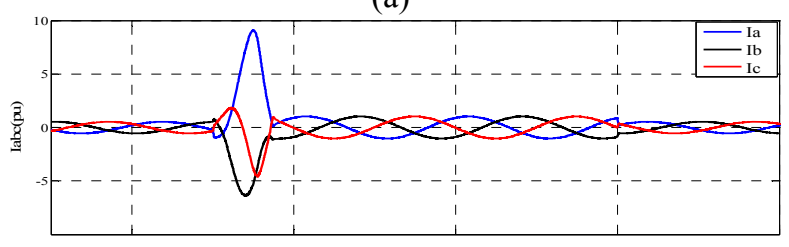

(b)

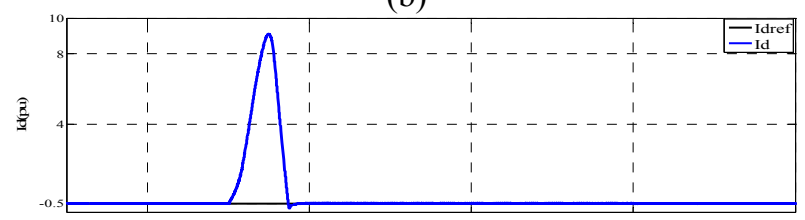

(c)

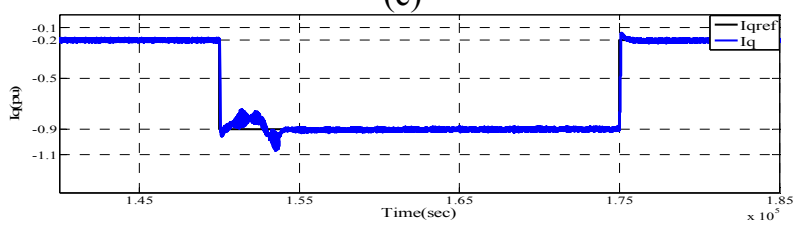

Figure 14. Simulation results of the transient response of the multivariable-PI controller during step changes in q-axis at $V_{d c}=700 \mathrm{~V}$. (a) Line currents. (b) d-component of the currents. (c) qcomponents of the currents.

(a)

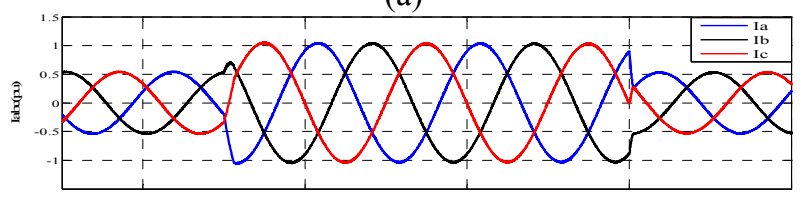

(b)

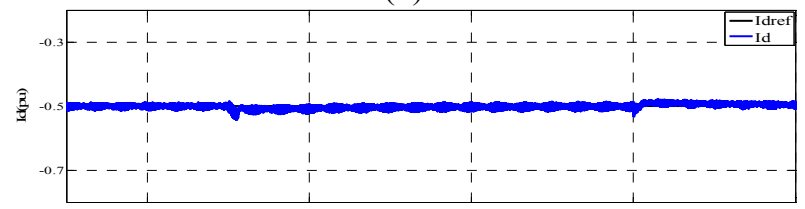

(c)

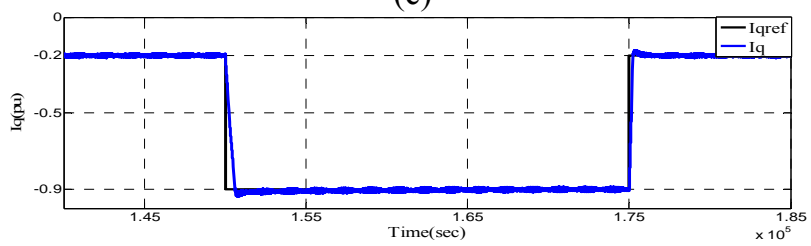

Figure 15. Simulation results of the transient response of the multivariable-PI controller during step changes in q-axis at $V_{d c}=200 \mathrm{~V}$. (a) Line currents. (b) d-component of the currents. (c) qcomponents of the currents. 
(a)

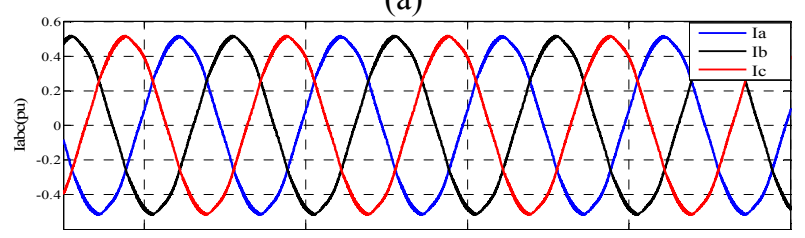

(b)

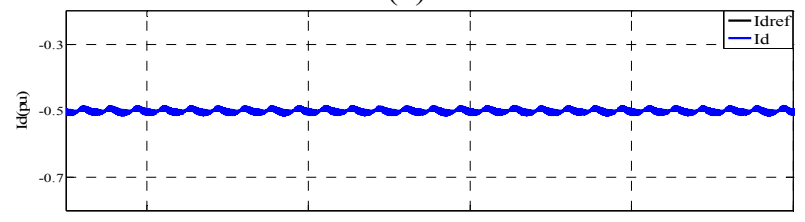

(c)

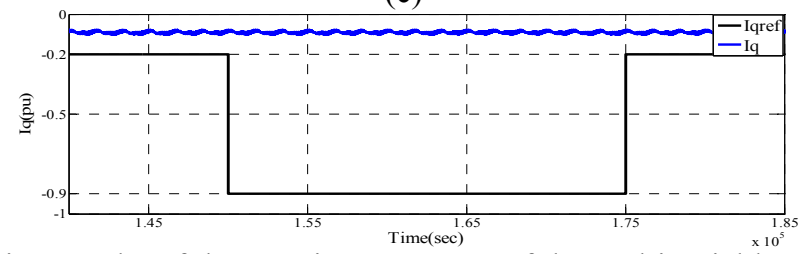

Figure 16. Simulation results of the transient response of the multivariable-PI controller during step changes in q-axis at $V_{d c}=100 \mathrm{~V}$. (a) Line currents. (b) d-component of the currents. (c) qcomponents of the currents.

It could be inferred from simulation results where the multivariable PI controller imposed less transient and more decoupling capability between $\mathrm{d}$ and $\mathrm{q}$ axis components of the current during the changing process of the $V_{d c}$. For example when the q component reference value has been changed, the $i_{q}$ is regulated at the desired value faster than the conventional control strategy and the $i_{d}$ experienced much less transient too. In fact as it was expected, the multivariable control strategy has withstand more, respect to the changing the DC link voltage because of the integrator terms which have been used in the decoupling blocks and also eliminating the feed forward signals. According to the boundary quantities which has been considered for the current references signals $\left(i_{d}\right.$ and $\left.i_{q}\right)$, for both control strategies, an standard range for DC link voltage has been resulted by changing consequently the $V_{d c}$.

Due to the simulation results and the values of Table I, for the two aforementioned controllers the range follows as:

1. Conventional controller: $150 \mathrm{~V}<V_{d c}<200 \mathrm{~V}$

2. Multivariable-PI controller: $200 \mathrm{~V}<V_{d c}<300 \mathrm{~V}$

These values are obtained within the worst step changes in reference signals and for special parameters.

\section{Conclusion}

In this paper the structure of the two conventional and multivariable control strategy has been represented. Due to the importance of the tracking the references signals which have been specified for the controller, the effect of the DC link voltage as one of the most important parameters of the system has been investigated. It has been demonstrated where the multivariable control strategy has less transient and more decoupling capability between $d$ and $q$ axis components of the current during the step changes which have been occurred in the various DC link voltage of the VSC. Finally, based on the considering the worst step changes in the references signals and trying a wide range of the DC link voltage, a particular range has been resulted for it. It has been depicted where if the $V_{d c}$ is out of this specific range, it will 
either have negative effects on the controller's performance or causes signal tracking not occur at all which means system is unstable.

\section{References}

[1] S. B. Kjaer, J. K. Pedersen, and F. Blaabjerg, "A review of single-phase grid-connected inverters for photovoltaic modules," IEEE Trans. Ind. Appl., vol. 41, no. 5, pp. 12921306, Sep./Oct. 2005.

[2] B. C. Rabelo, W. Hofmann, J. Lucas da Silva, R. Gaiba de Oliveira, and S. R. Silva, "Reactive power control design in doubly fed induction generators for wind turbines," IEEE Trans. Ind. Electron., vol. 56, no. 10,pp. 4154-4162, Oct. 2009.

[3] H. Akagi, "Active harmonic filters," Proc. IEEE, vol. 93, no. 12, pp. 2128-2141, Dec. 2005.

[4] M. Sedighy, S. B. Dewan, and F. P. Dawson, "A robust digital current control method for active power filters," IEEE Trans. Ind. Appl., vol. 36,no. 4, pp. 1158-1164, Jul./Aug. 2000.

[5] P. G. Barbosa, L. G. B. Rolim, and E. H. Watanabe, "Control strategy for grid-connected DC-AC converters with load power factor correction converters," Proc. Inst. Elect. Eng.-Gener. Transmiss. Distrib., vol. 145,no. 5, pp. 487-491, Sep. 1998.

[6] L. Hassaine, E. Olias, J. Quintero, and M. Haddadi, "Digital power factor control and reactive power regulation for grid-connected photovoltaic inverter," Renew. Energ., vol. 34, no. 1, pp. 315-321, Jan. 2009.

[7] M. Saeedifard, R. Iravani, and J. Pou, "A space vector modulation strategy for a back-toback five-level HVDC converter system," IEEE Trans. Ind. Electron., vol. 56, no. 2, pp. 452-466, Feb. 2009.

[8] S. Buso, S. Fasolo, L. Malesani, and P. Mattavelli, "A dead-beat adaptive hysteresis current control," IEEE Trans. Ind. Appl., vol. 36, no. 4,pp. 1174-1180, Jul./Aug. 2000.

[9] D. N. Zmood and D. G. Holmes, "Stationary frame current regulation of PWM inverters with zero steady-state error," IEEE Trans. Power Electron., vol. 18, no. 3, pp. 814-822, May 2003.

[10] D. N. Zmood, D. G. Holmes, and G. H. Bode, "Frequency-domain analysis of three-phase linear current regulators," IEEE Trans. Ind. Appl., vol. 37, no. 2, pp. 601-610, Mar/Apr. 2001.

[11] C. Schauder and H. Mehta, "Vector analysis and control of advanced static VAR compensators," Proc. Inst. Elect. Eng.-Gener. Transmiss. Distrib., vol. 140, no. 4, pp. 299-306, Jul. 1993.

[12] M. P. Kazmierkowski and L. Malesani, "Current control techniques for three-phase voltage-source PWM converters: A survey," IEEE Trans. Ind. Electron., vol. 45, no. 5, pp. 691-703, Oct. 1998.

[13] E. Twining and D. G. Holmes, "Grid current regulation of a three-phase voltage source inverter with an $L C L$ input filter," IEEE Trans. Power Electron., vol. 18, no. 3, pp. 888895, May 2003.

[14] B. Bahrani, S.Kenzelmann and A. Rufer, "Multivariable-PI-based dq current control of voltage source converters with superior axis decoupling capability," IEEE Trans. Ind. Electron., vol. 58,no. 7, pp. 3016-3026, Jul. 2011.

[15] A. Sato and T. Noguchi, "Voltage-source PWM rectifier-inverter based on direct power control and its operation characteristics," IEEE Trans. Power Electron., vol. 26, no. 5, pp. 1559-1567, May 2011.

[16] F. Schettler, H. Huang and N. Christl, "HVDC transmission systems using voltage sourced converters - design and applications", IEEE Summer Power Meeting, July 2000, Vol.2, pp 715-720.

[17] P. H. Divshali, A. Alimardani, S.H. Hosseinian, M. Abedi, "Decentralized cooperative control strategy of microsources for stabilizing autonomous VSC-based microgrids," IEEE Trans. Power Systems., vol. 27, no. 4, pp. 1949 - 1959, Nov. 2012. 
[18] O. Ellabban, J. Van Mierlo, P. Lataire, “A DSP-based dual-loop peak DC-link voltage control strategy of the Z-source inverter," IEEE Trans. Power Electron., vol. 27, no. 9, pp. 4088 - 4097, Sep. 2012.

[19] T. L. Vandoorn, B. Meersman, L. Degroote, B. Renders, L. Vandevelde, "A control strategy for islanded microgrids with DC-Link voltage control," IEEE Trans. Power Delivery., vol. 26, no. 2, pp. 703 - 713, April. 2011.

[20] X. Yuan, F. Wang, D. Boroyevich, Y. Li, and R. Burgos, "DC-link voltage control of a full power converter for wind generator operating inweak-grid systems," IEEE Trans. Power Electron., vol. 24, no. 9, pp. 2178-2192, Sep. 2009.

[21] H. Bühler, Réglage des Systèmes d'Électronique de Puissance, vol. 1, 2 and 3, Théorie. Lausanne, Switzerland: PPUR, Presses Polytechniques et Universitaires Romandes, 1997.

[22] C. Bajracharya, "Control of VSC-HVDC for wind power", Specialization project, NTNU, Jan. 2008.

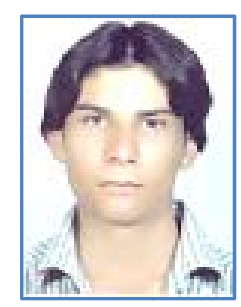

Hesam Rahbari Magham obtained his B.Sc degree in Electrical Engineering from Shiraz university of technology of Shiraz, Iran in 2011.Currently, he is an M.Sc student in Electrical Engineering at Amirkabir University of Technology, Tehran, Iran. His research interests include power system and power transformer monitoring, HVDC transmission systems and micro-grids.

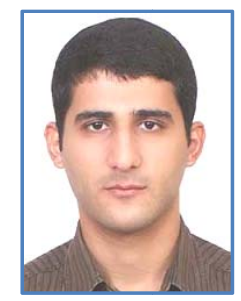

Erfan Ma'ali Amiri received his B.S. degree in electrical engineering from Noshirvani Babol university, Iran, in 2011.He is currently working toward the M.S. studies in electrical engineering in Amirkabir University of technology (Tehran Polytechnic), Tehran, Iran. His research is focused on power systems, digital signal processing, micro-grids.

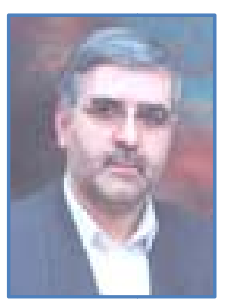

Javad Shokrollahi Moghani was born in Tabriz, Iran, in 1956. He received his B.S. and M.S. in Electrical Engineering from the South Bank Polytechnic, London, England and the Loughborough University of Technology, Loughborough, England, in 1982 and 1984, respectively. From 1984 to 1991 he was with the Department of Electrical Engineering, Amirkabir University of Technology, Tehran, Iran. He received his Ph.D. in Electrical Engineering from Bath University, Bath, England, in 1995. After graduating he returned to the Amirkabir University of Technology where he has been ever since. His current research interests include DC-DC converters, electric drives and electromagnetic system modeling and design using FEM. 


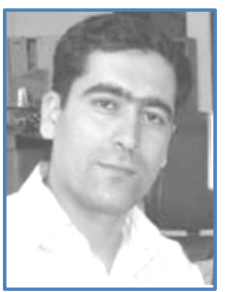

drives.

Babak Abdi (S'07) was born in Tehran, Iran, in 1976. He received the B.S. degree in electrical engineering from the University of Hormozgan, Hormozgan, Iran, in 2002, and the M.S. degree in electrical engineering from Amirkabir University of Technology (Tehran Polytechnic), Tehran, in 2005, where he is currently working toward the Ph.D. degree. He is a faculty member of Islamic Azad University, Damavand Branch, Tehran. His research interests include power electronics, application of reliability in power electronics, electromagnetic interferences, and electrical machines and

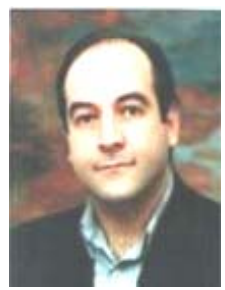

G. B. Gharehpetian received his BS, MS and Ph.D. degrees in electrical engineering in 1987, 1989 and 1996 from Tabriz University, Tabriz, Iran and Amirkabir University of Technology (AUT), Tehran, Iran and Tehran University, Tehran, Iran, respectively, graduating all with First Class Honors. As a Ph.D. student, he has received scholarship from DAAD (German Academic Exchange Service) from 1993 to 1996 and he was with High Voltage Institute of RWTH Aachen, Aachen, Germany. He has been holding the Assistant Professor position at AUT from 1997 to 2003, the position of Associate Professor from 2004 to 2007 and has been Professor since 2007. He was selected by the ministry of higher education as the distinguished professor of Iran and by IAEEE (Iranian Association of Electrical and Electronics Engineers) as the distinguished researcher of Iran and was awarded the National Prize in 2008 and 2010, respectively. He is the author of more than 650 journal and conference papers. His teaching and research interest include power system and transformers transients and power electronics applications in power systems. 